\title{
Blind spots and adverse conditions of care: tuberculosis screening of migrants in France and Germany
}

\section{Janina Kehr}

Published as : "Blind Spots and Adverse Conditions of Care: Screening Migrants for Tuberculosis in France and Germany." Sociology of Health \& Illness 34, no. 2 (February 1, 2012): 251-65. https://doi.org/10.1111/j.14679566.2011.01415.x.

Abstract

$$
\begin{aligned}
& \text { Tuberculosis (TB) is an infectious disease that declined significantly throughout the } 20^{\text {th }} \\
& \text { century. Large-scale TB screening of entire populations in France and Germany has thus been } \\
& \text { replaced by active screening of risk-groups, particularly migrants. The article engages with its } \\
& \text { problems and practices on three levels: by looking at the way information on migrants as an } \\
& \text { at-risk group is produced through disease surveillance data; by analysing how such at-risk } \\
& \text { group data influence local screening practices and by showing which political and medical } \\
& \text { problems arise in the field. I overturn the discussion about screening and surveillance of } \\
& \text { migrants as a risk-group by showing that it is not the stigmatisation of migrants through } \\
& \text { disease risk that is most at stake, but the invisibility of the most vulnerable among them in } \\
& \text { disease surveillance data and the way restrictive national immigration policies interfere with } \\
& \text { and subvert local screening and treatment practices targeting them. The aim of my article is } \\
& \text { to promote a pragmatic sociology of screening, while paying attention to the practical } \\
& \text { complexities, political conditions and medical ambivalences of screening and follow-up care, } \\
& \text { especially when the migrant groups concerned are socially, politically and medically } \\
& \text { vulnerable. }
\end{aligned}
$$

Keywords: tuberculosis, screening, migrants, politics, care

\section{Introduction}

Tuberculosis (TB) is an infectious disease and until quite recently it was thought that it had been eradicated in France and Germany. The advent of effective antibiotic therapies after World War II and improved living conditions had resulted in declining rates of disease since the 1950s and the incidence of the 'white plague' had been reduced to manageable proportions by the 1960 s and 1970 s. As a result, state-controlled screening through chest radiography, which had constituted one of the bases of the French and German national TB control programmes in the post-war years, was widely abandoned (Ferlinz 1996). However, radiography screening did not disappear altogether and in the 1990s was targeted at 'high risk' groups, notably immigrants (Broekmans et al. 2002). ${ }^{1}$ In the 1990s immigrants had been shown to have a relatively higher incidence of TB than the the indigenous population. The response was a policy of active and targeted screening on a European level (Comité national d'élaboration du programme de lutte contre la tuberculose 2007, Diel 2007, Rieder et al. 
1994). Thus, having historically been considered a 'social disease' associated with poverty (Barnes 1995, Dubos and Dubos 1987), TB was now thought of as an immigrants' disease, both in epidemiology (Antoine and Che 2010, Brodhun et al. 2007) and in public discourse (Ho 2004, Kehr 2009, 2010, King 2003).

Most social science studies examining the TB screening of migrants focus on their construction as a high-risk group, thus showing that targeted TB screening is not politically innocent but directly linked to national politics, and in particular to the politics of (border) control (Bashford 2010, Craig 2007, Ho 2004, King 2003). These works contribute to the literature on the surveillance and control of at-risk groups through preventive public health measures (Brown 2000, Lupton 1999, Petersen and Lupton 1996). Analysing the discourses of immigration and the nation-state they describe the way public health policies construct different categories of risk, arguing that these categories justify enhanced interventionism and surveillance of migrants, revealing risk to be a central mechanism. It thus comes as no surprise that in these studies, the branding of migrants as beint at high risk is found to have stigmatising and politically exclusionary effects. It serves to strengthen state surveillance through public health arguments - a feature also reflected in historiographic studies carried out on the link between public health, immigration and infectious disease (Coker 2004, Keane and Gushulak 2001, Welshman and Bashford 2006).

One important contribution of these studies is to analyse the concrete aspects of medicine as a surveillance system. Compulsory screening of migrants for TB at entry comes as a pertinent example, as a direct connection between immigration policies, health regulations and population control exists. Yet these studies rely largely on discourse and document analysis to demonstrate their findings and do not sufficiently engage with the whole array of screening practices, which are not always compulsory and are not always directly linked with immigration policies. Very little attention is therefore paid to the practical problems, ambivalences and national differences that arise when migrants are targeted and screened. One exception is the work of John Welshman $(2000,2010)$ who examines targeted TB screening from a practical perspective. He describes migrant at-entry screening in England and Wales in the 1950s and 1960s. Welshman (2000) shows how a higher incidence of TB among immigrants has led to their surveillance through disease control measures like screening. Yet his study also shows that the screening surveillance system did not operate effectively in practice. Practical problems were faced by public health professionals during screening, such as a failure to organise follow-up care or linguistic and administrative difficulties in attempting to X-ray large numbers of migrants. This limited the actual impact of surveillance and control on migrants, and also the efficiency of diagnosis, thereby partially impeding migrants' early treatment for TB. Welshman's study thus partly contradicts the surveillance thesis proposed by most sociological studies on migrants as an at-risk group, showing its limitations and adverse effects.

Following the historical work of Welshman, my comparative study proposes to continue this line of research into the practicalities, differences and ambivalences of migrant screening. It takes the example of active TB screening in France and Germany, where no social science research has been conducted on this topic to date. Active TB screening, operationalised through chest X-rays, targets at-risk groups or legally defined groups either forcibly, as is the case for at-entry screening of migrants and workplace screenings or voluntarily. Rather than assuming that migrant screening is a problem per se, I ask: How do national disease surveillance data actually construct migrants as a high-risk group? How do high-risk group definitions influence (or not) local 
migrant screening practices and what other factors codetermine the way screening is operationalised? In the case of Roma and undocumented migrants, what political and medical problems arise following screening for TB?

I argue that the main issues of French and German TB screening today are about concrete politics and practices, which cannot be sufficiently taken into account by discourse analyses focusing on risk-constructions and surveillance medicine. ${ }^{2}$ I thereby try to overturn the theoretical discussion about screening and surveillance of migrants as an at-risk group by arguing: firstly, that it is not the stigmatisation of migrants through risk discourse that is most at stake in France and Germany, but the problem of not seeing the most vulnerable among them through crude disease surveillance data; secondly, that the practice of active screening for extremely vulnerable migrants is still an exception in both countries, yet for different reasons; and thirdly, that it is not the way that health risk is used in immigration discourses and politics that is most dangerous for migrants in France and Germany, where TB is neither a reason to be expelled nor a reason to have a residence permit refused. What is dangerous is the way in which restrictive immigration policies interfere with and subvert the voluntary preventive public health activities targeting them, creating difficulties in their early treatment and follow-up care. In arguing thus, the aim of my article is to promote a pragmatic sociology of screening that pays attention to the practical complexities, political conditions and medical ambivalences of screening and care, especially when the groups concerned are socially, politically and medically vulnerable.

\section{The study}

The present article is based on research undertaken for my PhD thesis on the contemporary fight against TB in France and Germany, for which I conducted ethnographic fieldwork during 2005 and 2010 in TB prevention centres of two major French and German cities. Through a multi-sited ethnography (Marcus 1995) I 'followed' TB as an object into multiple medical sites, in order to understand by comparison how TB is treated in practice by health professionals today: medically, socially, sanitarily and politically. My research is based on a combination of observation, interviews and the study of documents produced by the actors of the social worlds I studied (Pope 2005, Savage 2000) - working documents, guidelines, articles and standard forms. The study draws on more than 300 hours of annotated observation of the daily activities of TB prevention centres in France $(N>200)$ and Germany $(N>100)$ and informal conversations with doctors, nurses, social workers and public health officers, as well as 23 in-depth interviews with public health professionals (doctors, $N=8$; nurses, $N=5$; public health officers and programme managers, $N=8$; and social workers, $N=2$ ). All conversations, interviews and field notes cited in this article were held or taken either in French or in German and translated by the author.

I was admitted to the German TB prevention centre as an intern with the local public health administration. Access to the French TB prevention centres was obtained through direct telephone contact with the responsible public health officers, granting me permission to do research in the departmental public health centres. My identity as an anthropologist and my research objectives were disclosed from the beginning to all actors in both countries, in written as well as oral form, and I obtained permission to observe consultations. I bound myself to respect medical confidentiality. One patient declined my presence. My observations focused on verbatim interactions between health professionals and patients, on collegial conversations, on the 
practices of health professionals and on the material settings of the sites. Detailed notes were taken where possible and subsequently transcribed. The topics of the semi-structured interviews were identified from preliminary analyses of observational transcripts. They dealt with the practical as well as political and ethical problems of TB control and medical treatment, as identified by the health professionals. I thus not only observed the practices of the health professionals but also listened to them 'as if they were their own ethnographers' (Mol 2001: 15).

I analysed my data comparatively, using each national case to inform the analysis of the other. Following grounded theory (Glaser and Strauss 1967), my research questions were adapted to the study context (public health/France or Germany/professionals or patients) and refined as I carried out ethnography and analysis. I made comparisons not in an entirely symmetrical way but heuristically to elucidate blind spots and to problematise common assumptions (Nader 1994). To do so, I first set the ethnographic data in their respective national contexts. After having identified the main issues through summarising, organising and coding the data, I compared the emerging topics and concepts transnationally. I was thus able to flesh out national particularities or binational commonalities on the one hand, and to localise or internationalise the results of the analysis on the other if the national frames were not sufficient for interpretation. In the present article, a slight dominance of the French data, where I did quantitatively more research, exists.

\section{Migrant screening: from the construction of risk to paradoxes of practice}

In the 1970s TB was nearly eradicated in western European countries. But at the end of the 1980s disease rates began to stagnate or to increase again and what had become an almost invisible infection made a reappearance on public health agendas. A European-wide TB 'task force' was set-up, known as the 'Wolfheze Workshop' (Antoine 2006), whose history has been recently described (Veen et al. 2011). One of the main goals of the guidelines following the workshops was to strengthen disease surveillance at national levels, as well as the targeted screening of migrants, 'based on mandatory . . . reports to identify population segments' (Veen et al. 2011, table I) at risk.

Blind spots: on bureaucratic disease surveillance and migrant patients In France and Germany, at-risk migrant groups are primarily defined through annual, nationwide disease surveillance reports based on so-called 'mandatory declarations' ${ }^{3}$ These declarations are transmitted to the disease surveillance institutions for each TB case detected. Being identified as being at risk thus depends on the epidemiological data available through the declarations and on the way in which epidemiological data are collected and produced. Besides clinical and bacteriological information on the TB cases, the mandatory declarations collect 'key variables' such as age, sex and country of birth, which are processed in the annual surveillance reports. In line with European guidelines, the explicit objective of the French and German annual reports is to elucidate disease risks in different population segments, in order to participate in 'meaningful and effective planning of prevention programmes' (Brodhun et al. 2007). Yet despite this aim, the annual surveillance reports based on mandatory declarations in both countries remain remarkably silent regarding TB control programmes and the development of migrant screening strategies.

In Germany, the mandatory declaration is generally very poor with regard to social information on declared TB cases, and particularly regarding key migrant data, like the individual's legal status, housing situation or date 
of immigration. The German declaration only collects information on the patient's country of birth and a revision of the mandatory declaration is - to my knowledge - not scheduled. This inattention to the social situation of TB patients in general and migrants' living conditions in particular is in part due to a broader societal blindness regarding inequalities in health and the specific problems migrants seeking health care might face, an issue that was publicly debated in Germany only in the 2000s (David 2001) - contrary to France, where the issue of social rights for migrants has been much debated since the 1970s (Mbaye 2009: 14). This is even more true for undocumented migrants, who have been absent from much public discourse and official statistics in Germany for a long time (Huschke 2011: 157), the health sector included, whereas French social movements early on put undocumented migrants' situation at centre stage in immigration debates (Mbaye 2009: 14). One very practical effect of the socio-political invisibility of undocumented migrants in the German public sphere is that preventive measures targeting them specifically, such as active TB screening, are discussed neither on a political nor practical level (Diel et al. 2004). Another effect is that recommendations in their regard neither figure in the German disease surveillance reports nor are they recommended in public health policies - a fact that is accentuated by the legalistic working practice of German public TB control, as I show below.

As one might expect, the situation is slightly different in France, one of the oldest European immigration countries. In the French context, the mandatory declaration is slightly more robust with regard to data collected about migrants' situations. There has been some recent debate around these mandatory reports and a working group has been set up to render them more socially meaningful in informing public health policies. In addition, a 2004 French Ministry of Health working group on preventive TB activities, targeting migrant populations specifically resulted in an expert report in 2005. In the last five years, the mandatory reports have thus come to include some data on the living situation of migrants, such as their housing situation and their date of arrival in France. Data on the diagnostic context have also been collected since 2010, specifying whether diagnosis occurred because the patient was seeking health care or due to contact tracing or at-entry screening. Yet there are still very few social facts collected in the French declarations, such as the social security status of migrant patients or their legal status. Thus, annual epidemiological reports lack information on the precise social situation that migrants face when falling ill, which have considerable influence on their disease risk and healthcare trajectories. Data on the diagnostic context are now collected in France and might help to elucidate the healthcare trajectories of different groups of migrant patients and this is thus a first step to educate policymakers on the (in)efficiency of some screening measures for migrants, such as at-entry screening. Yet, to be socially and practically meaningful, these data would need to be read with reference to information concerning migrant patients' social and legal situation - data which are politically and ethically sensitive to obtain and which are up to now collected in neither France nor in Germany, as I have shown.

Knowledge of the living conditions of migrants and the way they might influence the risk of disease remains very thin in both countries. This is cause for concern, as social and legal statuses are known to have a strong impact on susceptibility to TB (Antoine 2006, King 2003) and access to treatment (Borde and David 2003; Carde et al. 2002). When it comes to the development of targeted screening policies of population subgroups most at risk for disease, the national surveillance reports are therefore insufficient to inform public health practice, despite their political mission to do so. Rewritten in the same format with very similar expressions every year, 
the German and French surveillance reports based on mandatory declarations are, I would argue, a bureaucratic form of epidemiology but not an effective and practical means to inform prevention programmes, as their mission statements hold.

As Lyle Fearnley (2010) shows in his article, 'Epidemic Intelligence' and Alexander Langmuir captures in his concept of disease surveillance, disease reports were conceptualised after World War II to 'provide a continuous picture of the actual extent of an epidemic. Rather than providing the material for causal determinations, the disease report only enabled a "continuous watchfulness"' (p. 42) for the state. Relying on mandatory declarations, the annual TB reports bureaucratically fulfil the function of disease monitoring in French and German national spaces today. Yet, contrary to certain forms of epidemiology, be it the 'moral' epidemiology of Virchow or Villermin in the $19^{\text {th }}$ century or the social epidemiology of today (Krieger 2001, Lang et al. 2009), surveillance epidemiology is not greatly invested in correlating patterns of social life or living environment with the fact that certain sub-populations fall ill more often than others (Fearnley 2010). Politically 'neutral' state surveillance reports register the amount of disease within a national territory, yet they do not and cannot inform on ways to act on it, remaining silent about the underlying causes of disease - be they social or political. Disease surveillance reports based on socially thin mandatory declarations remain silent about the distribution of TB among migrant groups positioned in socially different places and therefore struggle with important blind spots. As a consequence, those people most likely to be at risk for TB today undocumented migrants and those without access to the healthcare system - remain invisible. Legalism and local know-how: differences in active screening In the German case, the absence of differentiated epidemiological knowledge on migrants at risk comes with strictly legalistic TB control. Active screening for TB in Germany is mandated by a public health law, the Infektionsschutzgesetz that is readily applied in the everyday work of TB prevention centres. This law commissions public TB centres - a branch of the local public health authority - to take chest X-rays of high-risk persons who are legally defined through residential criteria. People so defined include asylum seekers and refugees obliged to stay in a migrants' shelter until a residence permit is granted, homeless people asking for a place in a shelter, and people admitted to an old people's home. In short, those targeted are people residing in collective housing schemes as defined by a public health law.

This legalistic working mode is well demonstrated in a standard phrase I heard repeatedly from TB prevention centre doctors and social workers: 'We work according to the disease control law' the health professionals told me. All the German public health professionals I encountered confirmed that they approach their work purely on the basis of the law. The legal regulation did not leave any room for questions, for example, whether the screening of migrants in keeping with the law was sufficient for disease control and treatment success - questions that did come up in the French context, as I will show later on. Being legally codified, the German screening approach with criteria based on collective residence was, for the doctors and social workers of the German prevention centre, not open to question. They thus screened asylum seekers, refugees, displaced persons and homeless people applying for space in a shelter on a regular basis. Yet neither practical, ethical nor political questions concerning the targeting of specific groups, such as undocumented migrants, were asked in the German field. In effect, even if all migrants from high-incidence countries are defined as a high-risk group, and even if a large German epidemiological study could show that undocumented 
migrants are particularly at risk for disease (Hauer et al. 2006), there is no particular screening practice to target them if they do not belong to the administrative category of asylum seekers and displaced people (Diel et al. 2004). As a practical consequence, there is a complete absence of outreach screening of vulnerable migrants.

This is not quite the case in France, where outreach screening is heavily debated in the field. French public health professionals - nurses, programme managers and doctors alike - critique first and foremost the absence of precise data in relation to different migrant groups, as well as the absence of guidelines. During an interview, a public health nurse working in a French centre for TB control reflected on this absence in voicing his uncertainty regarding the groups he works with on a daily basis:

Do we really reach, well, let's say it this way: which, in fact, are all the types of populations which are most at risk? Do we really reach them? Are we really in contact with them? I am thinking, for example, of the Roma camp where we will be going. . . . Because, you know, tuberculosis exists mainly in these places, in disadvantaged neighbourhoods, and people from these neighbourhoods do not necessarily come into the prevention centre to see us. (Interview, nurse, France)

As can be seen through the nurse's words, the translation of group risk into active outreach screening comes with questions and uncertainty. The public health nurse I interviewed in 2005 asked himself whether he really knew the groups he should address and he wonders whether he is looking for TB in the right places, whether he can reach out to those who seem to him to be most at risk. The general, statistical knowledge about at-risk groups, as established by epidemiological surveys and national guidelines that go unquestioned in the German field, were not meaningful enough. In the French context, the general knowledge of at-risk groups in the national guidelines turned out to be insufficient to inform the nurse's practice in the field and did not represent the different groups of people he interacted with in his everyday work.

The responses of a programme manager of a regional TB screening programme in France set up in 2010, that I will call 'PrO-S-TB' (preventive outreach screening for TB), ${ }^{4}$ who worked in the same region as the nurse I had interviewed, are also intriguing. We talked about the origins of the PrO-S-TB, which was set up in collaboration with a local non-governmental organisation to reach extremely vulnerable migrants, like the Roma or undocumented migrants in overpopulated shelters. In the middle of our discussion the programme manager, seeming troubled, suddenly said:

You see, we found 12 TB cases for 300 X-rays passed within PrO-S-TB, this is huge, isn't it? The problem is, we don't have any comparative numbers, so we don't really know whether we should enlarge the circle of people we are targeting. We think that we are going in the right direction, but we don't really have good indications. There are the general guidelines, but not a lot more. (Conversation, Programme manager, France)

The statements of the nurse and the programme manager display a sense of uncertainty and unease concerning the targeted screening activities realised by the public health department. Health professionals explain their unease by the absence of meaningful guidelines - an unease that did not exist in Germany where a strong public health law overshadowed possible doubts. Yet the daily practice of the French public health 
professionals shows that despite this insecurity, they had pursued outreach screening activities targeting vulnerable migrants for many years, resulting in establishment of PrO-S-TB in 2010.

The implementation of PrO-S-TB on a local level demonstrates that the French public health professionals did not rely only on officialise risk-group knowledge in their daily practice or objectified, 'indisputable' knowledge (Desrosieres 2000). It was much too inaccurate for them. Nor did they rely on a general law, as was the case in Germany. They produced and used for their daily interactions with migrant groups what a public health doctor, in an interview we held about PrO-S-TB named empirical knowledge (savoir empirique) or knowhow. To my question as to why they chose to screen migrant shelters as one priority in the programme, the doctor replied:

It is about our experience. ... We have over 60 migrant shelters in the region. This is a huge number. From our experience in the field, we are acquainted with the living conditions in the shelters. If you count people actually living in a room with eight beds, you will be coming up with a number of 24 . We simply know that the situation there is very problematic. (Interview, Public health officer, France)

As the different quotations show, empirical knowledge, or know-how, about divergent TB risks among different migrant groups and their living conditions does exist in the field. The local working practice relying on knowhow and experience thus partly steps in for the insufficiencies and inaccuracies of the French national disease surveillance data and recommendations. Yet this politically sensitive and complex empirical knowledge remains local and screening thus largely depends on initiatives by engaged health professionals, which are often politically and ethically motivated. One effect of this contingency is that, in most places in France, vulnerable migrants are not systematically screened. In consequence, their TB is often diagnosed symptomatically at a very advanced stage (Bouchaud 2009). A programme like PrO-S-TB, seeking to reach out to vulnerable migrants, remains a localised exception.

As shown earlier, classificatory blind spots in bureaucratic disease surveillance and thus the vagueness and lack of specificity in the definition of at-risk groups make it difficult to develop meaningful and efficient screening activities for vulnerable migrants. In the French context, this situation exacerbates the rarity of active screening programmes, which are dependent on the engagement of public health professionals locally and thus are realised only in exceptional cases. In Germany, the very rigid, legalistic framework, which is out of step with migratory reality and its social dynamics, hinders local initiatives and accounts for the simple absence of targeted outreach screening for some migrant groups, like undocumented migrants. In Germany, such vulnerable migrants not only fall through the statistics in disease surveillance data but they also fall through the screening net, as defined and operationalised by law. Despite the different reasons for the relative absence of active screening for vulnerable migrants, the effects are comparable in both countries: screening approaches to vulnerable migrants continue to be 'suboptimal' (Hargreaves et al. 2009: 140). Yet even more is at stake, as I show in the last section using the example of PrO-S-TB and Roma patients in France. Once an exceptional, local screening programme started to function, it resulted in a tragic situation that depended for the most part on larger national immigration politics that created adverse conditions of care.

Public humanitarianism in France: on exceptional screening practice and adverse conditions of care 
The French immigration authorities implemented active screening of migrants in the form of 'at-entry' screening following World War II (Wluczka 2007). Since then, a medical exam including a chest X-ray has become obligatory for all immigrants from non-European Union countries entering France legally for more than 3 months and is subject to significant fees. Yet as I have shown, undocumented migrants are not captured by this strategy, either statistically or practically. To this end, the French National Programme to Fight Tuberculosis has recommended the active screening of particularly vulnerable migrants in 2007, like undocumented migrants, but also those residing in overpopulated shelters or those with an ambiguous residential status like the Roma. Nevertheless, such screening programmes are barely realised in France. The screening programme PrO-S-TB, which I discuss in more detail, is thus rather exceptional in both senses of the word: exceptional, because the targeted screening of undocumented migrants and Roma is not commonly practised in France; and exceptional because the PrO-S-TB relies on humanitarian, and thus exceptional, conditions of care-giving (Ticktin 2006).

PrO-S-TB is a pilot screening project put in place by an allocation the Ministry of Health accorded to the local public health administration where I did my research. It was set up after a series of highly contagious TB cases were discovered in the region, together with a worrying stagnation of the local disease rates. Two screening activities were established. One consists of screening the inhabitants of migrant shelters using a mobile X-ray unit. The other activity, to be discussed, consists of a collaboration of the public health department with a local charitable health centre, and screens patients without health insurance arriving at the health centre. In practice, most of their patients are undocumented migrants and Roma.

At a public conference presenting PrO-S-TB, the doctor working in the charitable health centre talked about the reasons for the collaboration between public and humanitarian institutions:

Why should we actively screen for tuberculosis in our health centre? Because our patients' social profiles comprise many conditions for tuberculosis. Our patients are migrants from high incidence countries and they suffer from extreme poverty, poor health, identity controls and everyday harassment. For years we have longed for the active TB screening of our patients, but we could not come up with a solution. And then the miracle in 2010: the local department of public health proposed a collaboration. (Activist doctor, conference transcript, France)

What the activist doctor was enthusing about was the implementation of PrO-S-TB in collaboration with the local public health administration. In practice, the public health department positions a mobile X-ray unit behind the organisation's charitable health centre. Twice a month, the centres' patients - 'people whose living conditions one cannot even imagine', as the responsible public health officer put it (conference transcript, France) - thus get the opportunity to have a free lung X-ray on site.

With this measure, the public TB control unit attempts to reach extremely vulnerable migrants excluded from the public healthcare system and at entry screening, by screening them at the place where they actually seek and get care, the charitable health centre. As such, the collaboration between a humanitarian organisation and the local public health department can be seen as a form of public humanitarianism for the sections of the population the French state usually does not care for and does not care about. Unpublished data, collected by the public health office, indicate that the screening yield for active TB by PrO-S-TB in the 
health centre is huge: out of 363 X-rays taken in 2010, 13 TB cases were detected, 11 of which were bacteriologically confirmed. Statistically, this is a yield of 35.8 TB cases per thousand screened (local statistics, conference transcript, France). For comparison: the median yield of immigrant screening in Europe at entry is 2.83 per thousand, as a recent meta-analysis shows (Arshad et al. 2010). Comparing these figures to the local data, even accounting for statistical imprecision, shows that at-entry screening is more than ten times smaller than the outreach screening of undocumented migrants by PrO-S-TB at the health centre. The juxtaposition of these numbers shows that the screening of excluded and vulnerable groups through a local publichumanitarian programme, set up with the help of local knowledge regarding their care-seeking trajectories and living conditions, seems a success - at least on a diagnostic level.

Nevertheless, an important question has not yet been asked: what happens to those persons diagnosed with TB? Are they actually treated? The programme manager explained to me that they had made 'good progress on the question of care' (Conversation transcript, programme manager, France). She told me that at the beginning of the programme, they did not even consider that treatment could be a problem. But rapidly they realised that in order to treat patients with TB they had to set up a proper system of assistance so that the patients would actually be hospitalised and treated. The assistance scheme includes translators throughout the hospitalisation process, social workers and community mediators. Yet, once the assistance was functioning and the patients started free treatment, another problem emerged, first and foremost in regard to the medical care of the Roma: treatment completion. Only one in eight treated Roma patients is known to have actually completed it (local statistics, conference transcript, France). This fact led the public health officer and the clinician to ask whether it was a good idea to put Roma patients in treatment in the first place; a question they answered negatively in some cases. Given the danger of multi-resistance when treatment is abandoned early, as well as the possible severe side effects for the patient in the absence of medical supervision, the public health doctor jointly with the clinician took an ethically painful medical decision: to abstain from treatment for those of their Roma patients who are not in a life-threatening condition.

How can it be that public health doctors and clinicians jointly agree not to treat a patient suffering from a curable disease? The reasons are political rather than ethical, as the explanations of the public health doctor on the reasons for treatment failure show: she told me that at the inception of the programme there was a political consensus among immigration and public health administrations not to deport Roma patients in treatment and to maintain residential rights for those communities living in the same camp as the person diagnosed with TB. Yet the immigration authorities did not honour the agreement and so some treated patients or their family members were obliged to leave the French territory. Patients thus had to leave the country within a few weeks and were unable to complete treatment in France. In her explanation, the doctor clearly explained that interruption of treatment was not the Roma patients' fault. On the contrary, treatment interruption was seen as a logical effect of restrictive immigration policies in regard to Roma communities. Treatment completion was thus seen as a political impossibility and - in consequence - to begin treatment was to act irresponsibly in medical terms.

The example reveals that it is very much the political discrimination of the Roma that impedes there treatment completion, and thus hinders their continuous care from screening to diagnosis and treatment, a fact of which public health professionals are well aware. The example, furthermore, shows that an apparent 
preventive solution to high TB incidence- a screening programme with a huge diagnostic yield - has had paradoxical effects. It was adapted to a particular group of vulnerable migrants and was effective in identifying new TB cases. But despite diagnostic efficiency, the strategy turned out to have serious adverse effects for public health and individual care, namely, the possible creation of multi-resistance to treatment and thus the decision to withhold antibiotic treatment from people who are most vulnerable to disease. This last ethnographic example of practice shows that tackling the problem of TB screening by finding the right places and reaching out to those people most at risk is not sufficient - neither for disease control nor for the treatment of those unfortunate enough to have the disease. Active screening of the people empirically known to be at high risk is a politically pragmatic reaction to their vulnerability, yet it does not lead to a practical solution to cure them from a curable disease.

The screening measure I talked about played out in a socio-political context, where access to health care is extremely difficult for the Roma and where, additionally, French immigration policies have restricted their residential rights. The European polemic on the situation of the Roma in France in the summer of 2010 (Willsher 2010) is very relevant here, showing their extreme marginalisation in the public space (Nacu 2010). In her article 'Where ethics and politics meet', Miriam Ticktin (2006: 36) shows how a political 'climate of closure' that led to immigration restrictions led to the extension of humanitarian reasoning about immigrants who suffer from disease. In the case of PrO-S-TB, this is partly also the case. Public structures like the local TB control service had to rely on humanitarian structures to tackle the problem of TB control, which is by law the duty of public health authorities, yet their intervention was in vain. Even if the purpose of the local screening policy is to include and treat through early diagnosis those people whose social exclusion puts them at great risk of active TB and diagnostic delay, exclusionary immigration policies interfered, creating adverse conditions of care. The consequence is a paradoxical medical situation: abstaining from treating the most vulnerable patients despite successful diagnostic screening and readily available medication for curing the disease.

\section{Conclusion}

What I described in the last section is an ethically tragic situation where it became politically impossible to treat those discovered through active screening to be most at risk for TB. The last example as well as the previous ones lead me to conclude that on a practical public health level, the active screening of migrants for TB needs to be reconceptualised. This could be done via the production of politically more meaningful epidemiological data, by supporting local knowledge, creativity and reflexivity, and by more closely articulating the nexus of TB screening and care. I have argued that migrants as an at-risk group are conceptualised in France and Germany in bureaucratic epidemiological disease surveillance data through crude categories such as nationality or place of birth. These categories do not sufficiently take into account the migrants' heterogeneous risk profiles in the country of immigration, which are very much influenced by their social situation and legal status, in short, their 'condition as migrant patient' (Fassin 2001), which differs greatly from one national context to another and between different migrant groups. Routine national epidemiological surveys, which should inform TB control policies, thus lack precise and localised data for those people most in need of screening and care. A first step to remedy this situation would be to include more information in the mandatory declarations, such as the legal 
status of migrants and their social security status, as well as data on the diagnostic context as has been implemented in France since 2010.

I have further argued that the public health objectives of targeted screening, namely, to treat those most vulnerable to TB, need to be articulated with the actual and often adverse political conditions of care, which are very dissimilar as they address differentially marginalised groups in different countries. If this is not done, even the most efficient targeted screening programme remains a symptomatic gesture towards controlling disease rather than a realistic option for treating people. My study thus shows the inherently political character of TB screening, particularly when Roma patients are concerned. Roma patients are paradoxical medicopolitical subjects, as their medical treatment interferes with different 'legal-administrative referentials' (Fassin 2001: 141). They are approached through two types of public politics that are mutually exclusive: an inclusionary one in the case of local disease control, and an exclusionary one in the case of national border control. In the current political climate it is the exclusionary approach that determines their conditions of care. Yet this does not go without contestation from health professionals. The screening and treatment of migrants thus do not only represent a struggle between the caring professions and social inequalities and national policies, which play out differently according to the 'migrants' condition' (Fassin 2001: 139); they are also political practices, which are implemented on contested terrains.

Finally, using the example of a screening activity targeting particularly vulnerable migrants, my study shows that it is not stigmatising and surveilling public health measures that are most dangerous for migrants, as social science studies investigating migrant screening have held so far, but their ineffectiveness, given political closure and social inequalities. My study has thus raised pragmatic political issues that have not been studied sufficiently by sociologists and anthropologists in regard to screening and at-risk groups so far. Yet such studies seem important for future research and might help to add to studies on the surveillance and control of at-risk groups, which are mainly based on discourse analyses and tend not to engage sufficiently with the practical and political problems that are of primary importance: the definition and operationalisation of group risk, access to diagnostic screening and the nexus of screening and care. From my ethnographic study I found that it is these topics that need to be integrated in the sociology of screening, especially when vulnerable migrants are concerned. On a theoretical level, problems of in/visibility and inclusion/exclusion that are the corollary effects of social segregation and discrimination (Farmer 2003; Fassin 2000) would need to be treated more closely, as well as the practical problems of treatment after diagnostic screening in medically clear, yet politically adverse conditions of care.

\section{Acknowledgements}

I am very thankful to the public health professionals who shared their working and thoughts with me. My gratitude also goes to Manuel Schwab, Natalie Armstrong, Helen Eborall and the anonymous reviewers of the Sociology of Health \& IIIness for their valuable and insightful comments on earlier versions of the manuscript. Thanks to Najla Rettberg for the English language editing. I warmly thank Didier Fassin and Stefan Beck, my PhD supervisors, for many stimulating discussions, as well as my graduate institutions for logistic support: the Institut de recherche interdisciplinaire sur les enjeux sociaux at the Ecole des hautes études en sciences sociales Paris and the Institut für Europäische Ethnologie at Humboldt University Berlin. The research was supported 
through a NaFöG PhD grant of the city of Berlin and a 6-month fieldwork grant of the Centre interdisciplinaire d'études et de recherches sur l'Allemagne.

\section{Notes}

1 In some European countries, as is the case for France and other former colonial powers (Welshman and Bashford 2006) immigrants were targeted for TB screening early on. In France foreign workers have been screened on entering the country since the late 1940s (Wluczka 2007). For the past few years, at-entry screening for migrants has come under severe criticism and demands for its revision are made on account of its doubtful efficacy - economically as well as in regard to public health outcomes (Coker 2006, Dasgupta and Menzies 2005, Hargreaves et al. 2009, Klinkenberget al. 2009). For this argument, see also Kehr (2011) on tracing TB contacts and the thickness of social lives.

3 As TB is a notifiable disease, mandatory declarations are the primary source of national TB statistics. They are produced by French and German public disease surveillance institutions: the Institut de Veille Sanitaire in France and the Robert-Koch-Institute in Germany.

4 The name is a pseudonym.

\section{References}

Antoine, D. (2006) Tuberculose et migrations internationales en Europe de l'Ouest. Nanterre: Université Paris X Nanterre.

Antoine, D. and Che, D. (2010) Epidemiologie de la tuberculose en France: bilan des cas déclarés en 2008, Bulletin epidémiologique hebdomadaire, 27-28, XX, 289-93.

Arshad, S., Bavan, L., Gajari, K., Paget, S.N.J. et al. (2010) Active screening at entry for tuberculosis among new immigrants: a systematic review and meta-analysis, European Respiratory Journal, 35, 6, 1336-45.

Barnes, D. (1995) The Making of a Social Disease: Tuberculosis in Nineteenth-Century France. Berkeley: University of California Press.

Bashford, A. (2010) The Great White Plague turns alien: tuberculosis and Immigration in Australia, 1901-2001. In Condrau, F. and Worboys, M. (eds) Tuberculosis Then and Now. Perspectives on the History of an Infectious Disease. Montreal and Kingston: McGill-Queen's University Press.

Borde, T. and David, M. (2003) Gut versorgt? Migrantinnen und Migranten im Gesundheits- und Sozialwesen. Frankfurt am Main: Mabuse Verlag.

Bouchaud, O. (2009) Health care of vulnerable populations infected with TB and HIV, Bulletin epidémiologique hebdomadaire, 12-13, 119-21.

Brodhun, B., Altmann, D. and Haas, W. (2007) Bericht zur Epidemiologie der Tuberkulose in Deutschland für 2005. Berlin: Robert Koch-Institut.

Broekmans, J.F., Migliori, G.B., Rieder, H.L., Lees, J. et al. (2002) European framework for tuberculosis control and elimination in countries with a low incidence: recommendations of the World Health Organization (WHO), International Union Against Tuberculosis and Lung Disease (IUATLD) and Royal Netherlands Tuberculosis Association (KNCV) Working Group, European Respiratory Journal, 19, 4, 765-75.

Brown, T. (2000) AIDS, risk and social governance, Social Science \& Medicine 50, 9, 1273-84. 
Carde, E., Fassin, D. and Ferré, N. (2002) Un traitement inégal. Les discriminations dans l'accès aux soins, Migrations études, 106, XX, 1-10.

Coker, R. (2004) Compulsory screening of immigrants for tuberculosis and HIV, British Medical Journal, 328, 7435, 298-300.

Coker, R. (2006) Tuberculosis screening in migrants in selected European countries shows wide disparities, European Respiratory Journal, 27, 4, 801-7.

Comité national d'élaboration du programme de lutte contre la tuberculose. (2007) Programme de lutte contre la tuberculose en France 2007-2009. Paris.

Craig, G.M. (2007) 'Nation', 'migration' and 'tuberculosis', Social Theory and Health, 5, 267-84.

Dasgupta, K. and Menzies, D. (2005) Cost-effectiveness of tuberculosis control strategies among immigrants and refugees, European Respiratory Journal, 25, 6, 1107-16.

David, M. (2001) Migration und Gesundheit: Zustandsbeschreibung und Zukunftsmodelle. Frankfurt am Main: Mabuse Verlag.

Desrosieres, A. (2000) La politique des grands nombres. Histoire de la raison statistique. Paris: La Découverte.

Diel, R. (2007) Prävention und Kontrolle der Tuberkulose, Der Pneumologe, 4, 3, 187-93.

Diel, R., Rusch-Gerdes, S. and Niemann, S. (2004) Molecular epidemiology of tuberculosis among immigrants in Hamburg, Germany, Journal of Clinical Microbiology, 42, 7, 2952-60.

Dubos, R. and Dubos, J. (1987) The White Plague: Tuberculosis, Man, and Society. New Jersey: Rutgers University Press.

Farmer, P. (2003) Pathologies of Power. Health, Human Rights, and the New War on the Poor. Berkeley, Los Angeles and London: University of California Press.

Fassin, D. (2000) Repenser les enjeux de santé autour de l'immigration, Homme et Migration, 1225, 5-12.

Fassin, D. (2001) Une double peine. La condition sociale des immigrés malades du sida, L'Homme, 160, $137-62$.

Fearnley, L. (2010) Epidemic intelligence. Langmuir and the birth of disease surveillance, Behemoth: A Journal on Civilisation, 3, 3, 36-56.

Ferlinz, R. (1996) Die Tuberkulose in Deutschland und das Deutsche Zentralkommitee zur Bekämpfung der Tuberkulose, In Konietzko, N. (ed,) 100 Jahre Deutsches Zentralkommitee zur Bekämpfung der Tuberkulose (DZK). Der Kampf gegen die Tuberkulose. Frankfurt am Main: PMI Verlagsgruppe.

Glaser, B.G. and Strauss, A.L. (1967) The Discovery of Grounded Theory: Strategies for Qualitative Research. Chicago: Aldine Publishing Company.

Hargreaves, S., Carballo, M. and Friedland, J. (2009) Screening migrants for tuberculosis: where next? Lancet Infectious Disease, 9, 3, 139-40.

Hauer, B., Kunitz, F. Sagebiehl, D. et al. (2006) Abschlussbericht. Untersuchungen zur Tuberkulose in Deutschland: Molekulare Epidemiologie, Resistenzsituation und Behandlung. Berlin.

Huschke, S. (2011) Die Grenzen humanitärer Versorgung. In Bornschlegel, W., Frewer, A. and Mylius, M. (eds) Medizin für Menschen ohne Papiere: Menschenrechte und Ethik in der Praxis des Gesundheitssystems. Göttingen: VandR unipress.

Ho, M. (2004) Sociocultural aspects of tuberculosis: a literature review and a case study of immigrant tuberculosis, Social Science \& Medicine, 59, 4, 753-62. 
Keane, V. and Gushulak, B. (2001) The medical assessment of migrants: current limitations and future potential, International Migration, 39, 2, 29-42.

Kehr, J. (2009) The politics and poetics of migrant tuberculosis: modelling a 'social disease' in French public health. In Kalitzkus, V. and Twohig, P.L. (eds) The Tapestry of Health, IIIness and Disease. Amsterdam: Rodopi.

Kehr, J. (2010) Geographien der Gefahr. Warum wieder über die Tuberkulose gesprochen wird. In Dilger, H. and Hadolt, B. (eds) Medizin im Kontext. Krankheit und Gesundheit in einer vernetzten Welt. Frankfurt am Main: Peter Lang Verlag. pp. 151-69.

Kehr, J. (2011) L'épaisseur des vies sociales. A propos du dépistage de la tuberculose. In Vailly, J., Kehr, J. and Niewöhner, J. (eds) De la vie biologique à la vie sociale. Approches sociologiques et anthropologiques. Paris: La Découverte.

King, N.B. (2003) Immigration, race and geographies of difference in the tuberculosis pandemic. In Gandy, M. and Zumla, A. (eds) The Return of the White Plague: Global Poverty and the New Tuberculosis. London: Verso Press.

Krieger, N. (2001) Theories for social epidemiology in the 21st century: an ecosocial perspective, International Journal of Epidemiology, 30, 4, 668-77.

Lang, T., Kelly-Irving, M. and Delpierre, C. (2009) Inégalités sociales de santé: du modèle épidémiologique à l'intervention. Enchaînements et accumulations au cours de la vie, Revue d'Épidémiologie et de Santé Publique, 57, 6, 429-35.

Lupton, D. (1999) Risk and Sociocultural Theory. New Directions and Perspectives. Cambridge: Cambridge University Press.

Marcus, G.E. (1995) Ethnography in/of the world-system. The emergence of multi-sited ethnography, Annual Review of Anthropology, 24, 95-117.

Mbaye, E.M. (2009) La santé des immigrés en France: controverses autour d'un paradigme, Hommes et Migrations, 1282, 6-19.

Mol, A. (2001) The Body Multiple: Ontology in Medical Practice. Durham: Duke University Press.

Nader, L. (1994) Comparative consciousness. In Borofsky, R. (ed.) Assessing Cultural Anthropology. New York: McGrens-Hill.

Nacu, A. (2010) Les Roms migrants en région parisienne: les dispositifs d'une marginalisation, Revue européenne des migrations internationales, 26, 1, 141-60.

Petersen, A. and Lupton, D. (1996) The New Public Health: Health and Self in the Age of Risk. London: Sage.

Pope, C. (2005) Conducting ethnography in medical settings, Medical Education, 39, 12, 1180-7.

Rieder, H.L., Zellweger, J.P., Raviglione, M.C., Keizer, S.T. et al. (1994) Tuberculosis control in Europe and international migration, European Respiratory Journal, 7, 8, 1545-53.

Savage, J. (2000) Ethnography and health care, British Medical Journal, 321, 7273, 1400-2.

Ticktin, M. (2006) Where ethics and politics meet, American Ethnologist, 33, 1, 33-49.

Veen, J., Migliori, G.B., Raviglione, M.C. et al. (2011) Harmonisation of TB control in the WHO European region: the history of the Wolfheze Workshops, European Respiratory Journal, 37, 4, 950-9. 
Welshman, J. and Bashford, A. (2006) Health screening. Tuberculosis, migration, and medical examination: lessons from history, Journal of Epidemiology and Community Health, 60, 4, 282-4.

Welshman, J. (2000) Tuberculosis and ethnicity in England and Wales, 1950-1970, Sociology of Health \& IIIness, $22,6,858-82$.

Welshman, J. (2010) Importation, deprivation, and susceptibility. Tuberculosis narratives in postwar Britain. In Condrau, F. and Worboys, M. (eds) Tuberculosis Then and Now. Perspectives on the History of an Infectious Disease. Montreal: McGill-Queen's University Press.

Willsher, K. (2010) France's deportation of Roma shown to be illegal in leaked memo, say critics, The Guardian. Available at http://www.guardian.co.uk/world/2010/sep/13/france-deportation-roma-illegal-memo (last accessed 15 September 2011).

Wluczka, M. (2007) Du contrôle sanitaire à la prévention, les enjeux de la santé des migrants, Les Tribunes de la santé, 17, 4, 39-45. 